\title{
Alterações Climáticas, Incremento dos Desastres e Necessidades Preventivas
}

\author{
Pedro Ananias Gomes Catanho ${ }^{1}$ (D), Emerson Mariano da Silva ${ }^{1,2}$ (D), Davi Teixeira Gomes ${ }^{1}$ (D), \\ José Maria Brabo Alves ${ }^{1,2}$ \\ ${ }^{1}$ Centro de Ciências e Tecnologia, Universidade Estadual do Ceará, Fortaleza CE, Brasil. \\ ${ }^{2}$ Mestrado Profissional em Climatologia e Aplicações nos Países da CPLP e África, \\ Universidade Estadual do Ceará, Fortaleza, CE, Brasil.
}

Recebido em: 13 de Abril de 2020 - Aceito em: 8 de Agosto de 2020

\begin{abstract}
Resumo
Desastres naturais ocorrem desde os primordios, datando desde o surgimento do homem no planeta Terra, a cerca de 350 mil anos atrás. Estes tem modificado ecossistemas de forma a impactar aos mais variados tratos populacionais, qualidade de vida e outras atividades humanas. Desastres registrados no Brasil têm proporcionado significativas perdas, especialmente em áreas e regiões que concentram populações mais pobres e vulneráveis. Como hipótese, acreditamos que seja pertinente disseminação de informação sobre medidas prevenção e mitigação, específicas para cada vulnerabilidade identificada. A inserção de conhecimentos sobre gestão integrada de risco de desastres nas instituições de ensino superior apresenta-se como uma opção efetiva para a divulgação da cultura prevencionista e o fortalecimento de comunidades mais resilientes. Como objetivo geral buscar-se-á averiguar quais os fenômenos físicos naturais desencadeadores de desastres tem contribuído para retardar o desenvolvimento social e econômico. Tendo em vista que o estudo dos desastres é incipiente no país, optou-se por uma pesquisa exploratória e cujo sentido, teve o objetivo de nos proporcionar maior amplitude com o problema da pesquisa em epígrafe. No mundo contemporâneo é imprescindível que os gestores invistam em gestão de riscos e vulnerabilidades. Como sugestão, acredito que possamos levar este tema aos cursos de graduação, pós-graduação estrito e lato senso, para que todos tenham entendimento do assunto e possam disseminar de forma técnica científica as medidas estratégicas para mitigar os efeitos destrutivos dos fenômenos físicos naturais desencadeadores de desastres.
\end{abstract}

Palavras-chave: desastres naturais, gestão integrada de risco de desastre, disseminação.

\section{Climate Change, Disaster Increase and Preventive Needs}

\begin{abstract}
Natural disasters occurred since the emergence of man on planet Earth, about 350 thousands years ago. Its have been modified ecosystems in a way that can provide the most varied impacts population treatment, quality of life and others activities. Disasters in Brazil have led to significant losses, especially in areas and regions that concentrate the poorest and most vulnerable populations. As a hypothesis, we believe that it is pertinent to disseminate information on prevention and mitigation measures, specific to each identified vulnerability. The insertion of knowledge on integrated disaster risk management in higher education institutions presents itself as an effective option for the dissemination of prevention culture and the strengthening of more resilient communities. The general objective is to find out which natural physical phenomena have contributed to slowing down social and economic development. Given that the study of disasters is incipient in the country, we have opted for an exploratory research whose purpose was to provide us with greater scope with the problem of the research in question. In the contemporary world, it is essential that managers invest in risk and vulnerability management. As a suggestion, I believe that we can take this theme to the undergraduate, graduate and postgraduate courses strictly and broadly so that everyone has an understanding of the subject and can disseminate in a technical scientific way the strategic measures to mitigate the destructive effects of natural physical phenomena that trigger disasters.
\end{abstract}

Keywords: natural disasters, integrated disaster risk management, dissemination.

Autor de correspondência: Pedro Ananias Gomes Catanho, pedrogomescatanho@hotmail.com. 


\section{Introdução}

Desde o surgimento do "homem" no planeta Terra, há cerca de 350 mil anos atrás, os ecossistemas vêm sendo modificados com o intuito de propiciar atendimento às mais variadas demandas da humanidade, no que tange à qualidade de vida (vide o site História do Mundo). As alterações geográficas que o homem tem realizado, tanto em zonas urbanas quanto rurais, muitas vezes de forma empírica, contribuem para este ambiente "novo", com o surgimento de vulnerabilidades e riscos de desastres.

Desde o nível global, passando pelo nacional, até chegar aos níveis regional e local, tem-se verificado um crescente aumento do número de fenômenos físicos naturais desencadeadores de desastres. As modificações ambientais realizadas de forma inadequada, pelo desconhecimento das dinâmicas geomorfológicas, hidrológicas e pluviais que contemplam o ambiente nos espaços urbanos, do ponto de vista preventivo, são significativamente impactantes para esses sistemas, principalmente para os meios urbanos.

Ao longo da história humana, os assentamentos são estabelecidos próximos às margens de rios e córregos. Após quase toda a ocupação dos espaços urbanos considerados aedificandi (área em que é permitido erguer edificações.), onde os abastados constroem suas mansões, os cidadãos menos favorecidos buscam áreas non-aedificandi (área em que não é permitido erguer edificações). São áreas de encosta, que são buscadas, muitas vezes, por falta de oportunidades, de conhecimento dos riscos e pela necessidade de habitar próximo ao local do emprego.

Sob tal premissa, especialistas como Lavell (2004), Veyret (2007), Adams (2009), Beck (2011), Nunes (2017), dentre outros, têm observado uma elevada ocorrência de desastres naturais em vários lugares do mundo. Eles têm ocorrido na América Latina e também no Brasil. Não é diferente no estado do Ceará, região nordeste do país. As ações decorrentes da deterioração ambiental, com significativa influência das alterações climáticas, têm incrementado o registro de eventos desastrosos. Quanto a isso, ressalta-se que, no Ceará, foram enfrentadas, em 2009, chuvas intensas com danos humanos e prejuízos em 132 dos 184 municípios cearenses. Em outro extremo, o Ceará enfrentou desde 2011 seguidamente anos de seca so quais afetaram seus municípios socio-economicamente.

O fato é que o país enfrenta desastres anuais com significativas magnitudes. Isso proporciona perdas, especialmente em áreas e regiões que concentram populações mais pobres e vulneráveis. Dentre tais desastres, os que geram maiores perdas e danos são os relacionados à escassez de água, como secas, ou ao excesso, como inundações e deslizamentos de terra.

$\mathrm{O}$ estudo em epígrafe é justificado pelas reduzidas pesquisas relacionadas ao tema. Muitas dessas pesquisas são direcionadas a pontos restritos de um contexto com- plexo. Tratam os temas dos riscos e da vulnerabilidades de forma isolada. Porém a Gestão Integrada de Risco de Desastres, como o próprio nome diz, agrega uma gama do saberes, entre os quais a Geografia, a Matemática, a Estatística, as Ciências da Saúde, as Engenharias, a Física, a Biologia e tantas outras. Todas têm enorme potencial contributivo para fomentar o engrandecimento de conhecimentos e especificidades para a criação e a disseminação de uma cultura de prevenção a exemplo de países como Japão, Peru, Nicarágua e muitos outros.

Segundo Pinheiro (2015), há significativas dificuldades para compreender os processos da Gestão Integrada de Risco de Desastres no Brasil. O que permite o surgimento de diversos óbices na criação e disseminação de uma cultura de prevenção de desastres relacionados as alterações climáticas no país, conforme evidenciamos no estudo em epígrafe.

\footnotetext{
Temos, no Brasil, serias dificuldades parta compreender o significado do que seja defesa civil, prorteção e defesa civil, e ainda Gestão Integrada de Risco de Desastres. Consequentemenrte essa incertea e desconhecimento tende a se alastrar nos governos, nas areas setoriais, no legislartivo, no judiciario; enfim, torna-se dificil gerenciar algo considerado importante alpenas quando o desastre apresenta sua face desrtuidora (Pinheiro, 2015, p. 39).
}

Do exposto, são salutares diversos questionamentos. Um dos que mais inquietam, no momento, é saber quais conhecimentos urgem para que se permita interferir na redução do incremento dos desastres frente às alterações climáticas?

Como primeira hipótese, acredita-se que seja pertinente disseminar, nas áreas de risco, conhecimentos de medidas preventivas específicas para risco e vulnerabilidade, identificados no mapa de risco das áreas pré-delimitadas. Como segunda hipótese, entende-se que a introdução de conhecimentos sobre medidas preventivas nas instituições de ensino possa atingir uma gama maior, principalmente de pessoas jovens entre 14 e 20 anos de idade, as quais possam ser disseminadoras dos conhecimentos adquiridos em suas comunidades, sejam elas de risco ou não.

Por fim, e não menos importante, imagina-se ser mais eficiente a introdução dos conhecimentos de ações preventivas, mediante a inserção de conhecimentos sobre gestão integrada de risco de desastres, nas instituições de ensino superior. Estas poderão repassar para um contingente populacional ainda maior, permitindo a massificação dos conhecimentos adquiridos no seio da sociedade.

No presente estudo, como objetivo geral, busca-se averiguar e fazer um quantitativo de quais fenômenos físicos naturais são desencadeadores de desastres e têm contribuído para retardar o desenvolvimento social e econômico em várias áreas do globo, Ceará e Nordeste do Brasil. Também alertar sobre como é possível empreender esforços para prevenir, mitigar e estabelecer um melhor convívio planejado com essas adversidades. 
Dentre os objetivos específicos tem-se: comentar dentre o conjunto de fenômenos físicos naturais desencadeadores de desastres, quais os que exercem maior influência no retardo do desenvolvimento social e econômico; despertar, na academia, o interesse pelo tema, por tratar-se de um conjunto de atividades multidisciplinares.

\section{Material e Métodos}

Tendo em vista que o estudo fez uma busca síntese dos desastres naturais relacionando-os às alterações climimáticas e às possíveis medidas preventivas a serem dotadas para mitigar seus efeitos e danos, que este assunto pode ser considerado incipiente, do ponto de vista preventivo, optou-se por uma pesquisa exploratória e cujo propósito primário foi proporcionar maior amplitude de compreensão do problema. Checou-se antecipadamente a pertinência do assunto em discussão e verificaram-se outras pesquisas em áreas conjuntas que já foram ou estão sendo exploradas. Desta forma, ampliando-se a relevância do tema e a sua contribuição para a academia e para a sociedade como um todo, com informações nos dados coletados pela Coordenadoria de Proteção e Defesa Civil do Estado do Ceará, os quais são relativos implicitamente aos processos de decretação de situação de emergência, em geral, citados em estudos da literatura. Em suma, os dados usados no estudo foram de consultas de artigos e comunicações na mídia em geral para o Brasil e o mundo sobre desastres naturais. Os métodos de análise tiveram como base resultados de estudos e citações na literatura e mída em geral sobre desastres naturais.

\section{Referencial Teórico}

\subsection{Breve histórico de desastres no mundo, no Brasil e no Ceará}

Desde a origem do planeta Terra, a sinergia entre os sistemas terrestres propicia o surgimento dos fenômenos físicos climatológicos (tempestades, secas), hidrológicos (inundações, enxurradas), litológicos (terremotos e vulcanismo) e biológicos (epidemias e pandemias). Com estes, advêm diversos danos humanos, ambientais e materiais, com consequentes prejuízos econômicos e sociais, que globalmente têm chegado à casa dos bilhões de dólares.

Conforme verificado na Fig. 1, há variações em número de vítimas e de desastres informados em todo o mundo. Porém é importante destacar que, entre 1990 e 2012, houve desastres e que o pico de eventos foi em 2005. Embora com número de vítimas relativamente baixo, esse ano foi o maior em número de desastres.

Segundo Nunes (2017), o Brasil, entre os anos de 1960 e 2009, foi o nono país da América Latina em número de mortes por epidemia de meningite em 1970, com 1.500 óbitos; o décimo primeiro em mortes por inundação em 1967, com 785 óbitos, e o décimo nono em mortes por movimento de massa úmida em 1967, com 436 óbitos. Conforme destacam Musse et al. (2015, p. 3):

\footnotetext{
A epidemia de meningite surgida em São Paulo na década de 1970, época da ditadura, nos faz refletir o quanto a saúde está relacionada e até dependente de fatores externos importantes, como a política.
}

O relatório anual emitido pelo Centro de Pesquisas em Epidemiologia de Desastres - CRED, ligado à Universidade Católica de Louvain, na Bélgica, intitulado "Natural Disasters - 2018", o qual faz referência aos

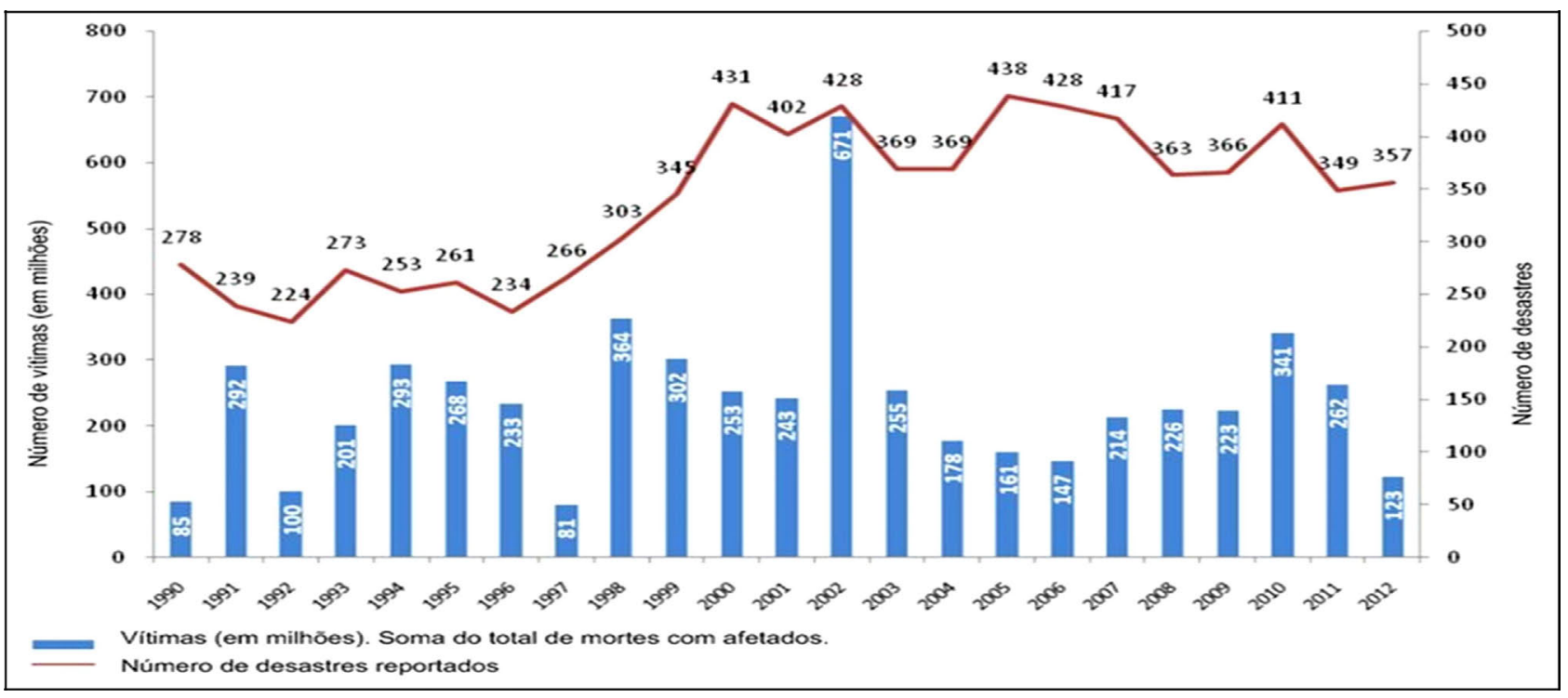

Figura 1 - Padrão de ocorrência e vítimas de desastres no mundo. Fonte: CRED (2013). 
eventos desastrosos do ano anterior, apresenta dados que merecem reflexão. Eles nos revelam o seguinte: em 2018, foram relatados 315 desastres no mundo; 11.804 vidas foram ceifadas por esses eventos; 68,5 milhões de pessoas tiveram suas vidas afetadas e os prejuízos em decorrência dos desastres foram orçados em 132 bilhões de dólares.

A maioria dos eventos de desastres tem ocorrido no continente asiático. Obviamente por possuir a maioria dos países do globo e também por apresentar um contingente populacional bem maior. Logo, segundo o relatório referido acima, esse continente amargurou $45 \%$ dos desastres; cerca de $80 \%$ da população ceifada; $76 \%$ das pessoas afetadas. Ainda de acordo com o relatório, a Indonésia obteve o record de morte, com $47 \%$ do total; a Índia, foi recordista em número de pessoas afetadas, com $35 \%$ do total (Fig. 1).

A fim de podermos ter uma dimensão do número de eventos desastrosos que têm ocorrido e seu incremento gradativo ano após ano, o relatório de 2018 do CRED fez um comparativo sobre a quantidade de desastres registrados entre os anos de 2008 e 2017 , período em que ocorreram 348 registros em todo o mundo, e somente em 2018 foram registrados 315 desastres relatados. Ou seja, os desastres registrados em 2018 correspondem a 90,51\% dos registros de toda uma década. Podemos verificar na Fig. 2.

Com relação aos dados da figura, evidencia-se que os maiores vilões, dentre os fenômenos físicos desencadeadores de desastres registrados, estão ligados à climatologia, à hidrologia e à meteorologia, os quais são as inundações, as tempestades e as secas. Ou seja, por excesso ou escassez de água.

Do total de registros compilados pelo CRED, verifica-se que em todos os continentes vêm ocorrendo esses fenômenos desencadeadores de desastres. E, sendo assim, os continentes foram afetados conforme dados da Fig. 3.

Como visto nos relatórios do CRED, no continente americano, em 2018, foram registrados 65 eventos de desastres. Tais fatos nos alertam para analisar e verificar o que tem ocorrido na América Latina e, com destacada evidência, no Brasil.

Segundo Nunes (2017), a América do Sul, desde os anos de 1960 até 2009, vem potencializando diversos eventos desastrosos, dentre estes, terremotos, inundações, vulcanismos, epidemias, movimentos de massa e tempestades, os quais ceifaram inúmeras vidas ao longo do período. A Tabela 1 apresenta os 20 desastres naturais que causaram mais óbitos, entendidos, então, como as maiores tragédias que marcaram as nações da América do Sul naquele período. Os registros mostram que esses eventos ceifaram 149.877 vidas, o Brasil aparece em três ocasiões.

Segundo o Centro de Coordenação para a Prevenção dos Desastres Naturais na América Central - CEPREDENAC (2003), os desastres podem destruir em horas toda uma infraestrutura que levou anos para ser edificada. Além disso, têm destruído ainda sonhos e ceifado vidas em todo o mundo.

Cada desastre arrasa, em poucas horas, com os sonhos e os esforços de muitos cidadãos e com logros de muitos anos de trabalho no desenvolvimento. Nas últimas décadas, têm falecido em torno de 3 milhões de pessoas em decorrência dos desastres de grande magnitude vinculados aos fenômenos naturais e sócio-naturais (CEPREDENAC, 2003, p. 5).

De fato, a cada ano, verifica-se a recorrência de eventos desastrosos em todo o planeta e com magnitudes cada vez mais severas em áreas que se julgavam seguras. Como exemplo, podemos citar o caso do terremoto seguido de tsunami e que provocou inundações que afetou o sistema de refrigeração da usina nuclear de Fukushima, culminando com um desastre secundário de explosão dessa mesma usina no Japão em 2011.

Segundo Nunes (2017), entre os anos de 1960 e 2000, alguns países da América Latina enfrentaram eventos desastrosos significativos. Eles são apresentados na Tabela 1.

É perceptível que há uma oscilação no número de eventos desastrosos nas décadas em epígrafe. Porém o

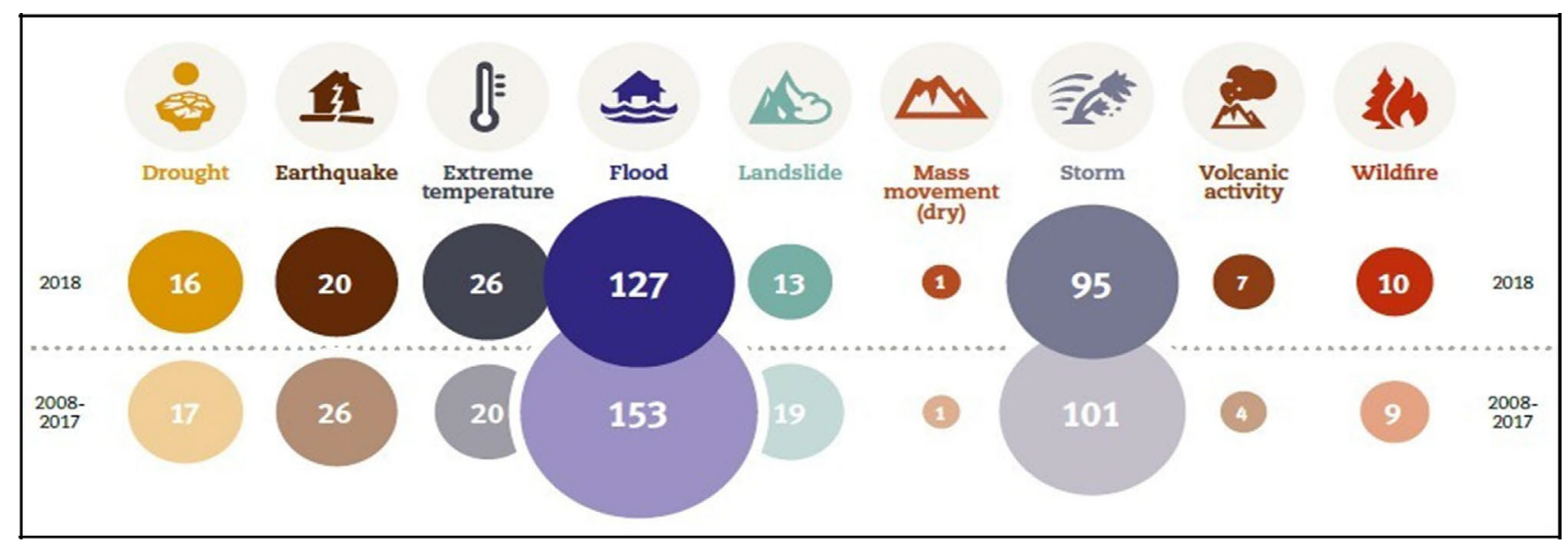

Figura 2 - Comparativo das ocorrências de desastres entre 2007-2017 e 2018. Fonte: CRED (2018). 


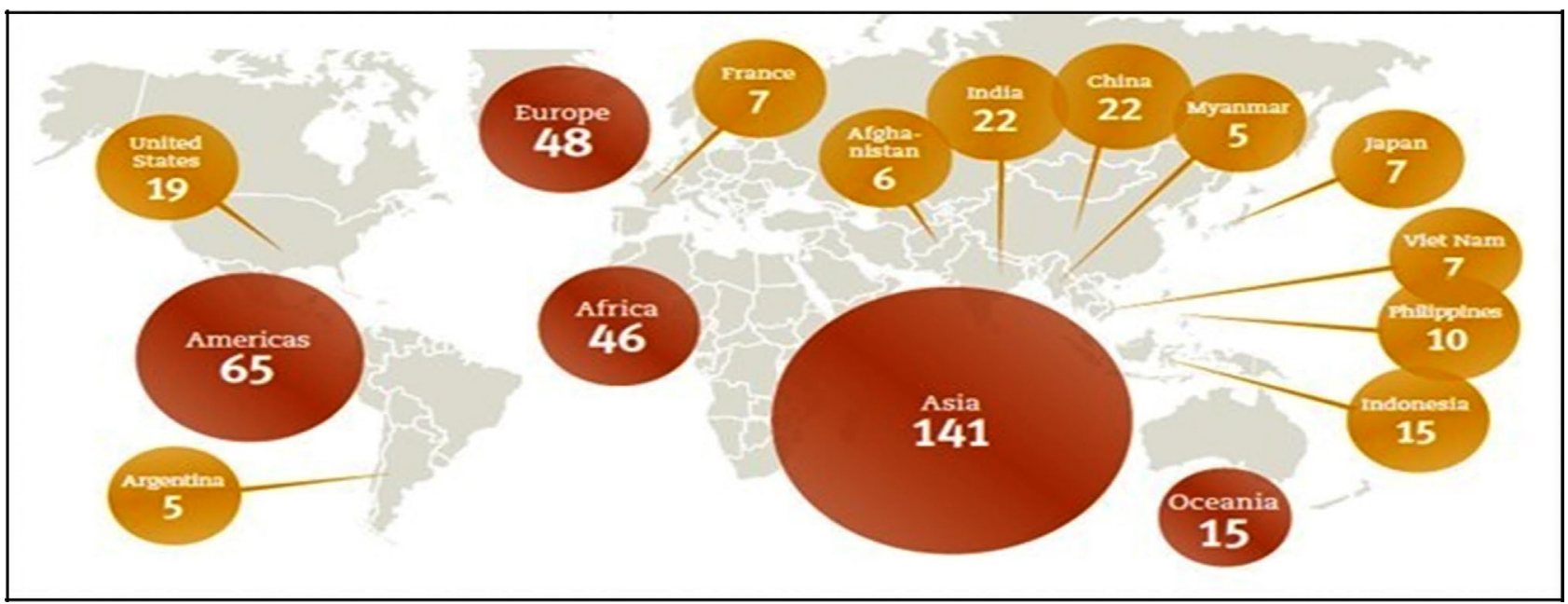

Figura 3 - Os 10 maiores tipos de desastres por continente. Fonte: CRED (2018).

Tabela 1 - Registro de desastres que produziram mortes, afetados e prejuízos entre 1960 e 2000. Fonte: adaptado de Nunes (2017).

\begin{tabular}{lccccc}
\hline Dano/década & 1960 & 1970 & 1980 & 1990 & 2000 \\
\hline Mortos & 5 & 5 & 6 & 3 & 1 \\
Afetados & 2 & 5 & 6 & 3 & 4 \\
Prejuízos & 0 & 1 & 10 & 4 & 5 \\
\hline
\end{tabular}

destaque está em verificar que em todas houve desastres, independente do que ocorreu.

Ainda de acordo com a CEPREDENAC (2003), os desastres e conflitos têm propiciado ao mundo prejuízos significativos em decorrência dos riscos e vulnerabilidades existentes e da incipiente gestão de risco que ora é aplicada em todo o mundo, com maior observância nos países em desenvolvimento e subdesenvolvidos.

De 1991 a 2000, têm-se registrado em média 211 milhões de pessoas afetadas anualmente pelos desastres - 7 vezes a mais que a média das 31 milhões de pessoas anualmente afetadas por conflitos. As perdas associadas aos desastres excedem aos US\$ 90 bilhões de dólares anuais (CEPREDENAC, 2003, p. 5).

Verifica-se que, além dos danos humanos, os desastres produzem prejuízos econômicos e sociais enormes. Nas últimas décadas (Tabela 2), tem-se observado um crescimento em número e magnitude de fenômenos físicos desencadeadores de desastres em todo o planeta. Observou-se ainda que, embora os países tenham empreendido esforços para mitigar os desastres, estes não têm sido suficientes para reduzir as perdas.

Ao analisarmos essa Tabela 2, verifica-se que os desastres comumente têm relações com a climatologia, a hidrologia e a meteorologia, num total de 7 eventos em vinte. Porém, se levarmos em consideração as epidemias, que podem ou não ter relação com o clima, este número aumenta para $11 \mathrm{em}$ vinte. Ou seja, mais de $50 \%$ dos desastres podem ter relação com os eventos climatológicos, que, por sua vez, podem desencadear variações hidrológicas e meteorológicas, culminando em desastres.

Dos 49 anos de registros de fenômenos físicos desencadeadores de desastres na América Latina, o Brasil destaca-se com 2.721 óbitos em três eventos, dos quais dois são associados a fenômenos hidrológicos. Conforme esclarece o CRED (2016), os desastres de origem hidrológica ainda ocuparam a maior parcela das catástrofes naturais ocorridas ao longo da história, as quais, somente em 2016, corresponderam a $51,7 \%$ dos eventos, dentro de uma média de 50,5\% de registros em década 2006-2015 (CRED, 2016, p. 43).

Do exposto, e ao analisarmos os registros de desastres naturais emitidos pelo CRED, verifica-se que, ao longo das décadas seguintes até o momento, os desastres com maior número de mortes, que ocorrem com maior frequência em nível mundial, estão relacionadas ao clima, à hidrologia e à meteorologia, e que, se somados seus registros anualmente, pode-se chegar à média de 7 a 8 registros anuais. A Tabela 3 , detalha os eventos relacionados ao clima, à meteorologia e à hidrologia, nos últimos 13 anos, em número de mortes.

A Tabela 3 nos esclarece que, ano após ano, os fenômenos físicos desencadeadores de desastres, essencialmente os relacionados ao clima, à hidrologia e à meteorologia têm proporcionado perdas humanas e prejuízos significativos, desviando recursos que poderiam ser empregados no desenvolvimento das cidades para a recuperação dos danos decorrentes das catástrofes. A seguir esboçaremos algumas considerações sobre os desastres no Brasil.

\subsection{Os desastres no Brasil}

O Brasil é um país com dimensões continentais, com $8.511 .000 \mathrm{~km}^{2}$, e uma diversidade geomorfológica, climatológica e cultural sem igual. Com uma área tão vasta e 
Tabela 2 - Os 20 desastres naturais, na América Latina, que causaram mais óbitos entre 1960 e 2009. Fonte: Nunes (2015, p. 81). Adaptado de GuhaSapir, Below e Hoyois (s.d.). Grifos nossos.

\begin{tabular}{|c|c|c|c|c|}
\hline $\mathrm{N}^{\circ}$ ord. & País & Tipo de desastre & data & $\mathrm{N}^{\mathrm{o}}$ de óbitos \\
\hline 1 & Peru & Terremoto & $31 / 05 / 1970$ & 66.794 \\
\hline 2 & Venezuela & Inundação & $15 / 12 / 1999$ & 30.000 \\
\hline 3 & Colômbia & Vulcão & $13 / 11 / 1985$ & 21.800 \\
\hline 4 & Peru & Epidemia & $18 / 08 / 1991$ & 8.000 \\
\hline 5 & Chile & Terremoto & $21 / 05 / 1960$ & 6.000 \\
\hline 6 & Equador & Terremoto & 05/03/1987 & 5.000 \\
\hline 7 & Peru & Movimento de massa seca & $10 / 01 / 1962$ & 2.000 \\
\hline 8 & Peru & Epidemia & $31 / 01 / 1991$ & 1.726 \\
\hline 9 & Brasil & Epidemia $^{*}$ & 01/01/1974 & 1.500 \\
\hline 10 & Colômbia & Terremoto & $25 / 01 / 1999$ & 1.186 \\
\hline 11 & Brasil & Inundação ** & $23 / 01 / 1967$ & 785 \\
\hline 12 & Peru & Epidemia & 01/01/1992 & 690 \\
\hline 13 & Colômbia & Movimento de massa úmida & 27/09/1987 & 640 \\
\hline 14 & Chile & Inundação & 01/07/1965 & 600 \\
\hline 15 & Peru & Movimento de massa úmida & $18 / 03 / 1971$ & 600 \\
\hline 16 & Peru & Terremoto & $15 / 08 / 2007$ & 593 \\
\hline 17 & Colômbia & Terremoto & $12 / 12 / 1979$ & 579 \\
\hline 18 & Peru & Tempestade & $24 / 12 / 1997$ & 518 \\
\hline 19 & Brasil & Movimento de massa úmida ${ }^{* * *}$ & $19 / 03 / 1967$ & 436 \\
\hline 20 & Colômbia & Terremoto & $01 / 11 / 1970$ & 430 \\
\hline- & - & Total de óbitos em 49 anos & - & 149.877 \\
\hline
\end{tabular}

* https://noticias.r7.com/saude/fotos/brasil-ja-teve-tres-epidemias-de-meningite-a-pior-foi-nos-anos-1970-01032019\#!/foto/1.

** https://www1.folha.uol.com.br/fsp/cotidian/ff0704201009.htm.

*** https://www.seropedicaonline.com/utilidades/artigos/deslizamento-maior-tragedia-do-brasil-foi-em-1967-na-serra-das-araras-1700-mortos/.

Tabela 3 - Demonstrativo dos maiores desastres em número de mortes nos últimos 13 anos. Fonte: o autor. Adaptado de CRED, disasters in numbers, 2006 a 2018.

\begin{tabular}{|c|c|c|c|}
\hline $\begin{array}{l}\mathrm{N}^{\circ} \\
\text { ord. }\end{array}$ & Ano & Tipos de evento relacionado ao clima & Total \\
\hline 01 & 2006 & Tempestade - Tufão 'Dorian’ e 'Bille’(2); Onda de calor (3); Onda de frio (1); Inundação (1); e Tsunami (1) & 8 \\
\hline 02 & 2007 & Ciclone - Sidr e Yemyin (2); Inundação (6); Deslizamento de terras (1); Onda de calor (1); & 10 \\
\hline 03 & 2008 & $\begin{array}{l}\text { Ciclone Nargis (1); Inundação (4); Tufão Fengshen 'Franck’ (1); Condições extremas de inverno (1); Furacão Hanna(1); e Movi- } \\
\text { mento de massa molhada (1). }\end{array}$ & 9 \\
\hline 04 & 2009 & $\begin{array}{l}\text { Inundação (2); Tempestade tropical ‘Ondoy’(1); Tufão ‘Morakot' e 'Pepeng' (2); Onda de calor (1); Ciclone ‘Aila' (1); e Furacão } \\
\text { 'Ida'(1). }\end{array}$ & 8 \\
\hline 05 & 2010 & Onda de calor (1); Enchente (2); Deslizamento de terra (2); Onda de frio (1). & 6 \\
\hline 06 & 2011 & Inundação (6); Tempestade tropical ‘Sendong'(1); e Tempestade (1) & 8 \\
\hline 07 & 2012 & Inundação (4); Onda de frio (3); Avalanche (1); e Ciclone tropical 'Bopha' (1) & 8 \\
\hline 08 & 2013 & Onda de calor (3); Inundação (3); Ciclone tropical (Haiyan)(1); e Onda fria (1). & 8 \\
\hline 09 & 2014 & $\begin{array}{l}\text { Onda de frio (1); inundação rápida (2); inundação fluvial (2); inundação com deslizamentos de terra(1); e Deslizamento de terra } \\
\text { (3). }\end{array}$ & 9 \\
\hline 10 & 2015 & Onda de calor (4); Deslizamento de terras(1); Cheias fluviais (2); e Inundação (1). & 8 \\
\hline 11 & 2016 & Inundação (6); Furacão ‘Matthew’ (1); e Onda de calor (1). & 8 \\
\hline 12 & $2017^{*}$ & Furacão 'Harvey', 'Maria' e 'Irma'(3); Incêndios(1); Inundações(2); Tufões 'Hato'(1); Tempo severo(1) & 8 \\
\hline 13 & 2018 & Inundação (4); Tempestade (1); e Onda de calor (1) & 6 \\
\hline - & - & Total de desastres & 104 \\
\hline
\end{tabular}

*Weather, Climate \& Catastrophe Insig (2017, p. 4). Disponível em: http://thoughtleadership.aonbenfield.com/Documents/20180124-ab-if-annual-reportweather-climate-2017.pdf. 
colonizada por povos de culturas muito distintas, percebese que o trato com o meio ambiente em geral é bem diversificado. Talvez, devido aos tratos culturais de cada região ou adquirido de outros povos que formaram colônias em nosso território.

Dentro dessa perspectiva, observa-se que o desenvolvimento urbano apresenta caráter distinto de acordo com a região e a população nela inserida. Seja nos aspectos físico, social, educativo, cultural e ideológico, ambiental e ecológico, político e institucional, científico e tecnológico, o país sofre influências positivas e negativas no trato com os sistemas ambientais, mais precisamente na litosfera, na hidrosfera e na atmosfera, o que reflete ingerência na biosfera. Na litosfera, o homem modifica o meio ao seu redor, construindo às margens de rios e lagos sujeitas a inundações ou em áreas de encostas, suscetíveis a deslizamentos e enxurradas. Além disso, aglutina resíduos sólidos em lixões, provocando a contaminação do lençol freático. Como forma de reduzir os volumes, quase sempre, ateia fogo, o que produz interferências na atmosfera local. E, como a grande maioria destes lixões está à margem de rodovias, ainda contribui para o risco de acidentes tecnológicos envolvendo diversos tipos de veículos.

Em relação aos fenômenos físicos naturais desencadeadores de desastres, há uma gama deles, aos quais podemos fazer referência. Porém, mencionaremos apenas os que estão relacionados ao clima, à hidrologia e à meteorologia, já que são os que mais contribuem para o número de eventos desastrosos no mundo e em nosso país, conforme visto anteriormente.
Em todas as regiões do Brasil, as alterações climáticas têm propiciado o incremento de desastres. Estes frequentemente estão associados à hidrologia, tais como enchentes, alagamentos, enxurradas, deslizamentos de massa úmida, vendaval, chuvas intensas dentre tantos outros. A Tabela 4, apresenta alguns desses eventos desastrosos em todo o território brasileiro em vários momentos da história do país. Segundo dados do O globo, n. 31234, 11/02/2019, caderno País, p. 5, disponível no site do Senado Federal do Brasil, o descaso com enchentes matou 2.500 pessoas no país em vinte anos.

Ao analisarmos a Tabela 4, fica claro que a região sudeste é significativamente propícia a eventos hidrológicos que se convertem em desastres. Porém, sazonalmente, outras regiões do país também apresentam situações de desastres semelhantes.

Segundo dados do Instituto Brasileiro de Geografia e Estatística - IBGE, o Brasil, num período de apenas 4 anos, deixou cerca de 1,4 milhões de desabrigados. Ainda esclarece que os anos entre 2008 a 2012 trouxeram outros prejuízos para diversos municípios brasileiros.

As enchentes atingiram, entre 2008 e 2012, cerca de 1.543 municípios, o equivalente a $27,7 \%$ das cidades do país, o que resultou em registros de 8.942 ocorrências, que deixaram 1,4 milhão de pessoas desabrigadas ou desalojadas (que tiveram que deixar temporariamente as suas casas) em todo o Brasil (Agencia Brasil, 2014).

Observa-se, então, que o país é carente de mais estudos sobre áreas de riscos e que se faz necessária a implan-

Tabela 4 - Eventos desastrosos decorrentes de fenômenos físicos naturais relacionados à hidrologia em vários momentos da história do país. Fonte: Cultur amix.com. https://meioambiente.culturamix.com/desastres-naturais/o-historico-de-enchentes-no-brasil-causas-e-tragedias.

\begin{tabular}{|c|c|c|c|}
\hline $\begin{array}{l}\mathrm{N}^{\circ} \\
\text { Ord. }\end{array}$ & Tipo de desastre & Ano & Local \\
\hline 01 & Enchentes & 1855 & Santa Catarina \\
\hline 02 & Enchentes & 1941 & Rio Grande do Sul \\
\hline 03 & Enchentes e Deslizamentos de terra & 1967 & São Paulo (Caraguatatuba) \\
\hline 04 & Enchentes & 1979 & Minas Gerais e Espírito Santo \\
\hline 05 & Enchentes e Deslizamentos de terra & 2008 & Santa Catarina \\
\hline 05 & Enchentes & 2009 & $\begin{array}{l}\text { Região Norte e Nordeste. Nas últimas semanas, ao menos } 43 \text { pessoas já morreram nas inundações } \\
\text { que assolam cerca de } 300 \text { municípios no Ceará (12 mortes), Amazonas (8), Maranhão (7), Bahia } \\
\text { (7), Alagoas (4), Pará (2), Sergipe (2), Pernambuco (1), Piauí, Paraíba e Rio Grande do Norte (os } \\
\text { três últimos sem óbitos confirmados), segundo dados da Defesa Civil Nacional e das defesas civis } \\
\text { estaduais. }\end{array}$ \\
\hline 06 & Enchentes & 2010 & Alagoas e Pernambuco \\
\hline 07 & $\begin{array}{l}\text { Chuvas intensas (inundações e Desli- } \\
\text { zamentos de terra) }\end{array}$ & 2010 & Rio de Janeiro (Morro Carioca e Angra dos Reis) e São Paulo \\
\hline 08 & Enxurrada & 2010 & Ceará (Crato) \\
\hline 09 & Enchentes e Deslizamentos de terra & 2011 & $\begin{array}{c}\text { Rio de Janeiro (Nova Friburgo, Teresópolis, Petrópolis, Sumidouro, São José do Vale do Rio } \\
\text { Preto, Bom Jardim e Areal) }\end{array}$ \\
\hline 10 & $\begin{array}{l}\text { Deslizamentos de terra na região ser- } \\
\text { rana do Rio }\end{array}$ & 2011 & Rio de Janeiro (Teresópolis, Petrópolis e Nova Friburgo) \\
\hline 11 & Deslizamentos e enchentes urbanas & 2013 & Rio de Janeiro (Duque de Caxias, Xerém) \\
\hline
\end{tabular}


tação do fortalecimento das defesas civis municipais e estaduais bem como da nacional, a fim de propiciar dados mais completos sobre as necessidades de cada localidade, através da construção de uma mapa consolidado sobre os riscos de desastres, não só naturais mas também tecnológicos, já que também é um ponto crucial para desviar recursos em detrimento de um desenvolvimento sustentável no país, como bem preceituam os Objetivos de Desenvolvimento do Milênio - ODM, estabelecidos pela Organização das Nações Unidas - ONU, no ano de 2000, com o objetivo global de reduzir a pobreza extrema, tendo o Brasil sido um dos países signatários.

É de bom alvitre ressaltar a ausência de planejamento para o desenvolvimento urbano conforme os preceitos do ODM, segundo uma pesquisa realizada em 2013 pelo Instituto Brasileiro de Geografia e Estatística - IBGE, descrita no perfil básico dos municípios, na qual foi revelado - no Gráfico 44 - o percentual de municípios. Segundo o instrumento de planejamento - Brasil - 2013, apenas $9,4 \%$ dos 5.570 municípios brasileiros possuem algum Plano Municipal de Gestão de Risco (IBGE, 2013, p. 106).

Contudo, possivelmente, no âmbito do território brasileiro, os prefeitos e seus assessores, não têm levado em consideração obras estruturais com características compatíveis com os fenômenos físicos naturais desencadeadores de desastres, bem como não têm acompanhado a dinâmica das alterações sociais e econômicas que o país tem enfren- tado ao longo das últimas décadas em decorrência das alterações climáticas. Em várias regiões, estados, municípios e localidades, as enxurradas, as enchentes, os deslizamentos de terra e os alagamentos têm proporcionado um constante desafio aos gestores e cidadãos da nossa sociedade, em especial para os estratos populacionais menos favorecidos.

\subsection{Os desastres no Ceará}

O estado do Ceará tem suas peculiaridades em relação aos desastres naturais. Segundo as defesas civis do estado e municipio de Fortaleza, os mesmos estão quase sempre relacionados ao excesso ou à escassez de precipitações pluviométricas. Porém também ocorrem, no estado, terremotos, vendavais, chuvas de granizo, erosão costeira, dentre outros, conforme Tabela 5.

Ao analisarmos a Tabela 5, verifica-se que a maioria dos eventos de desastres relatados estão intimamente relacionados ao clima (seca e estiagem), à meteorologia (vendaval), à Hidrologia (enxurrada, inundação, enchente, chuva de granizo e deslizamento), os demais não estão relacionados com o estudo em epígrafe.

A cada ano, o estado vem enfrentando mais e mais fenômenos físicos desencadeadores de desastres. Estes, por sua vez, têm contribuído para ampliar os dados estatísticos relacionados aos danos e prejuízos em decorrência destes mesmos fenômenos. A Tabela 6 mostra alguns registros desses eventos recorrentes no estado do Ceará.

Tabela 5 - Eventos naturais que foram registrados no Ceará. Fonte: adaptado de Castro (2003).

\begin{tabular}{|c|c|}
\hline Eventos & Caracterização \\
\hline Estiagem & $\begin{array}{l}\text { Resulta da redução das precipitações pluviométricas, do atraso dos períodos chuvosos ou da ausência de chuvas previstas para } \\
\text { uma determinada temporada. }\end{array}$ \\
\hline Seca & $\begin{array}{l}\text { Do ponto de vista meteorológico, a seca é uma estiagem prolongada, caracte- rizada por provocar uma redução sustentada das } \\
\text { reservas hídricas existentes. }\end{array}$ \\
\hline $\begin{array}{l}\text { Enxurrada/ inundação } \\
\text { brusca }\end{array}$ & $\begin{array}{l}\text { São provocadas por chuvas intensas e concentradas, em regiões de relevo acidentado, caracterizando-se por produzirem súbi- } \\
\text { tas e violentas elevações dos caudais, os quais escoam-se de forma rápida e intensa. Nessas condições, ocorre um desequilí- } \\
\text { brio entre o continente (leito do rio) e o conteúdo (volu- me caudal), provocando transbordamento. }\end{array}$ \\
\hline $\begin{array}{l}\text { Enchente/ inundação gra- } \\
\text { dual }\end{array}$ & $\begin{array}{l}\text { As águas elevam-se de forma paulatina e previsível; mantêm-se em situação de cheia durante algum tempo e, a seguir, } \\
\text { escoam-se gradualmente. }\end{array}$ \\
\hline Alagamento & $\begin{array}{l}\text { As águas são acumuladas no leito das ruas e nos perímetros urbanos por for- tes precipitações pluviométricas, em cidades com } \\
\text { sistemas de drenagem deficientes. }\end{array}$ \\
\hline Vendaval & $\begin{array}{l}\text { São perturbações marcantes no estado normal da atmosfera. Deslocamento violento de uma massa de ar, de uma área de alta } \\
\text { pressão para outra de baixa pressão. Também chamados de ventos muito duros, correspondem ao número } 10 \text { da Escala de } \\
\text { Beaufort, compreendendo ventos cujas velocidades variam entre } 88,0 \text { a } 102,0 \mathrm{~km} / \mathrm{h} \text {. }\end{array}$ \\
\hline Terremoto & $\begin{array}{l}\text { São vibrações do terreno que provocam oscilações verticais e horizontais na superfície da Terra, geralmente ocasionadas por } \\
\text { rupturas e movimentação das rochas no interior da crosta terrestre. }\end{array}$ \\
\hline Erosão Marinha & $\begin{array}{l}\text { São o resultado do movimento das águas oceânicas, que atuam sobre as bor- das litorâneas, modelando o relevo de forma } \\
\text { destrutiva. Esse movimento das águas pode, também, modelar o relevo de forma construtiva, resultando em acumulação ma- } \\
\text { rinha e, consequentemente, dando origem a praias, restingas, recifes e tômbulos. }\end{array}$ \\
\hline Deslizamento & $\begin{array}{l}\text { Fenômenos provocados pelo escorregamento de materiais sólidos como solos, ro- chas, vegetação e/ou material de construção } \\
\text { ao longo de terrenos inclinados, denomi - nados de encostas, pendentes ou escarpas. Caracterizado ainda por movimentos } \\
\text { gravitacionais de massa que ocorrem de forma rápida e cuja superfície de ruptura é nitida- mente definida por limites laterais e } \\
\text { profundos, bem caracterizados. }\end{array}$ \\
\hline Chuva de granizo & $\begin{array}{l}\text { Precipitação sólida de grânulos de gelo, transparentes ou translúcidos, de forma esférica ou irregular, raramente cônica, de } \\
\text { diâmetro igual ou superior a } 5 \mathrm{~mm} \text {. }\end{array}$ \\
\hline
\end{tabular}


Do exposto na Tabela 6 , facilmente se percebe que os fenômenos físicos desencadeadores de desastres que ocorrem no âmbito do estado do Ceará são bem abrangentes e vão além de estiagens e secas, que, segundo dados da Superintendência de Desenvolvimento do Nordeste - SUDENE, comumente assolam 95\% das cidades cearenses. Fato que se agrava mais ainda, pois o Estado tem mais de $95 \%$ de território inserido no semiárido brasileiro, IPECE (2020).

Mediante essa nova delimitação, torna-se imperativo que os municípios que foram recém-incluídos, bem como os demais, atentem para a construção de seus planos de contingências frente aos fenômenos climáticos de estiagem e seca, principalmente, já que esses eventos ocorrem ciclicamente no território cearense.

Segundo Brasil (2017, p. 21) mediante o Ministério da Integração Nacional - MI, os planos de contingências devem ser elaborados na normalidade, quando são definidos os procedimentos, as ações e decisões que devem ser tomadas na ocorrência do desastre.

Nesse contexto, a PNPDEC atribui a responsabilidade pela execução do Plano de Contingência - PLANCON aos Municípios. Aos Estados e à União cabe a função de apoiar a execução local, a exemplo da criação, pelo governo federal, de um módulo específico de registro dos planos no Sistema Integrado de Informações sobre Desastres - S2ID.

Ainda como forma de deixar ainda mais evidente a questão dos desastres no país, o Instituto Brasileiro de Geografia e Estatística - IBGE, afirma que mais de dois mil municípios foram afetados por alagamentos, o que corresponde ao total de aproximadamente $30 \%$ do total de municípios brasileiros.

No Brasil, 2.065 municípios declararam ter sido atingidos por alagamentos nos últimos cinco anos da data de referência da pesquisa, ou seja, $37,1 \%$ do total dos municípios brasileiros. A maior concentração foi nas Regiões Sudeste (45,2\%) e Sul (43,5\%), e a menor na Centro-Oeste (19\%). Em todo o território nacional, 97,4\% dos municípios com mais de 500.000 habitantes regis- traram alagamentos, enquanto, na classe de municípios com até 5.000 habitantes, foram registrados os menores valores $(5,0 \%$, nas Regiões Norte e Centro-Oeste; e 11,5\%, na Região Nordeste) (IBGE, 2013, p. 97).

A descrição do IBGE, reforça a necessidade de buscarmos, através de pesquisas e estudos, compreender ainda mais as dinâmicas dos fenômenos físicos desencadeadores de desastres e, dessa forma, contribuir, em curto prazo, na qualificação de docentes e, a médio e longo prazos, na preparação de medidas estruturais e não estruturais com o objetivo de reduzir os impactos desses mesmos fenômenos na vida das pessoas Brasil a fora.

Ao nos referirmos aos contingenciamentos de medidas preventivas, entra-se numa outra seara da proteção e defesa civil, que, contemporaneamente, chamamos de Gestão Integrada de Risco de Desastres - GIRD, da qual trataremos a seguir.

\subsection{A gestão integrada de risco de desastres - GIRD}

A GIRD tem como foco a integração de todas as políticas como fulcro para prevenção dos riscos de desastres. A GIRD está alicerçada em três grandes ramos: a) Gestão Prospectiva de risco de desastres, destinada às atividades de gestão, que abordam e procuram evitar o desenvolvimento de novos ou maiores riscos de desastres; b) Gestão corretiva do risco de catástrofes, que são atividades de gestão que abordam e procuram corrigir ou reduzir o risco de desastres que já existe; e c) Gestão recuperativa do risco de catástrofes, que está direcionada para uma gestão onde foi realizada a gestão prospectiva. Porém os desastres superaram as projeções preventivas. Então, tem-se como tal a gestão de refazer ou recuperar para aperfeiçoar as medidas preventivas superadas. Nesse caso, como um exemplo prático e recente, pode-se elencar o muro de contenção de tsunami que existe no Japão, o qual foi superado pelas ondas decorrentes do maremoto

Tabela 6 - Registros de desastres no estado do Ceará. Fonte: Internet.

\begin{tabular}{|c|c|c|c|c|}
\hline $\begin{array}{l}\mathrm{N}^{\circ} \\
\text { ord. }\end{array}$ & Fenômeno & Localização & Ano & Fonte \\
\hline 01 & Enxurrada & Jericoacoara & 2019 & $\begin{array}{l}\text { https:/g1.globo.com/ce/ceara/noticia/2019/03/03/enxurrada-arrasta-cadeiras-durante- } \\
\text { forte-chuva-em-jijoca-de-jericoacoara-video.ghtml }\end{array}$ \\
\hline 02 & Enchente & Crato & 2020 & https://diariodonordeste.verdesmares.com.br/noticias/sobre/enchente-2.13258 \\
\hline 03 & Alagamento & Fortaleza & 2020 & https://diariodonordeste.verdesmares.com.br/noticias/sobre/enchente-2.13258 \\
\hline 04 & Chuva de granizo & $\begin{array}{l}\text { Massapê, Parambu e San- } \\
\text { tana do Cariri }\end{array}$ & 2017 & $\begin{array}{c}\text { https://g1.globo.com/ce/ceara/noticia/chuva-de-granizo-volta-a-ocorrer-no-interior-do- } \\
\text { ceara.ghtml }\end{array}$ \\
\hline 05 & $\begin{array}{l}\text { Deslizamento de } \\
\quad \text { Terra }\end{array}$ & Guaramiranga & 2019 & $\begin{array}{c}\text { https://diariodonordeste.verdesmares.com.br/editorias/metro/erosao-marinha-deixa-o- } \\
\text { ceara-em-situacao-de-alerta-1.1953627 }\end{array}$ \\
\hline 06 & Vendaval & Iguatu & 2014 & $\begin{array}{l}\text { https://esporte.band.uol.com.br/noticia/100000706048/vendaval-de-70-kmh-causa- } \\
\text { estragos-no-ceara.html }\end{array}$ \\
\hline 07 & Vendaval & Jaguaribe & 2019 & $\begin{array}{l}\text { https://www.opovo.com.br/noticias/ceara/jaguaribe/2019/10/20/vendaval-causa-estra } \\
\text { gos-em-jaguaribe-na-tarde-deste-domingo.html }\end{array}$ \\
\hline
\end{tabular}


em 2011 (Figs. 4 e 5). O governo japonês está ampliando seu potencial preventivo.

Nos últimos anos, começaram a surgir diferentes concepções e termos aplicados ao assunto da administração de riscos, alguns seguindo uma perspectiva tradicional e outros em busca de abordagens e estratégias inovadoras para lidar com a redução de vulnerabilidades e com a mitigação de desastres.

Segundo Lavell (2004), as vulnerabilidades e as ameaças, os fatores de risco se manifestam em condições concretas da existência humana ou físicas. São palpáveis, analisáveis e muitas delas factíveis de medir. Expressamse em condições de vida inseguras para a população (Lavell, 2004, p. 3).

Com essa mesma perspectiva, Veyret (2007), afirma que "os riscos naturais, assim como as catástrofes, que os traduzem em efeitos, estão correlacionadas à urbanização acelerada, a um ambiente degradado, à fragilidade da capacidade de resposta e, finalmente, ao subdesenvolvimento." (VeyRet, 2007, p. 83).

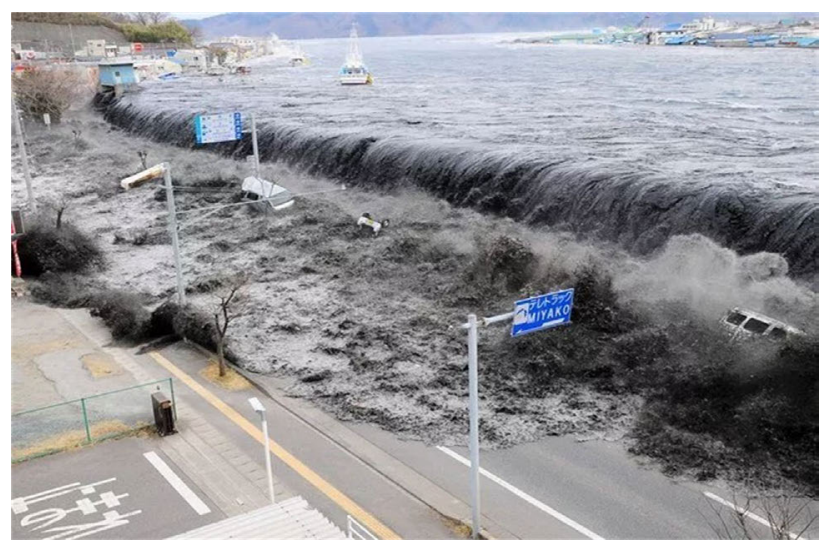

Figura 4 - Destruição na orla litorânea devido ao Tsunami ocorrido no Japão 2011. Fonte: https://reporternordeste.com.br/japao-constroi-torrespara-enfrentar-tsunami-de-mais-de-30-m-no-futuro/.

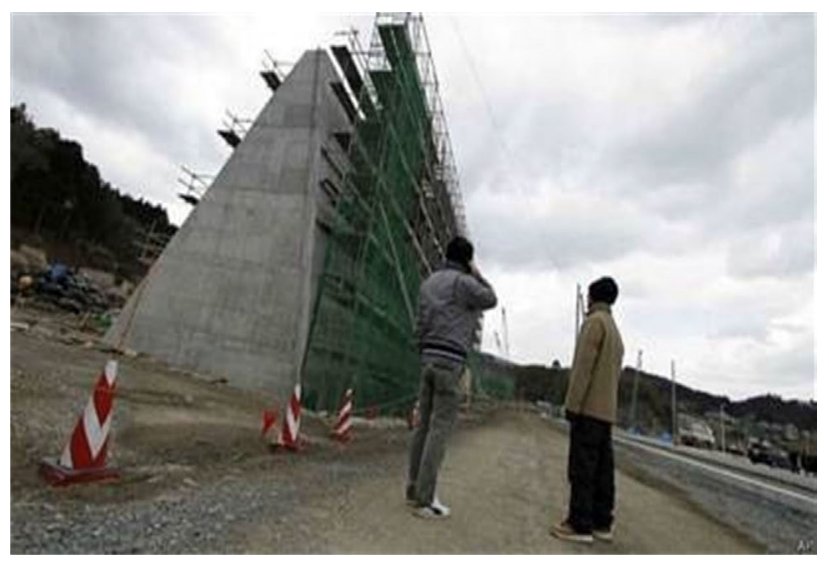

Figura 5 - Destruição do muro de contenção devido ao Tsunami ocorrido no Japão 2011. Fonte: https://www.bbc.com/portuguese/noticias/2015/ 03/150326_japao_muralha_tsunami_fn.
Por fim a GIRD tem como essencial o foco na prevenção, mediante a integração de várias políticas públicas que convergem para esse fim, com abrangência na avaliação e na análise de risco, bem como a execução de estratégias e ações específicas para controlar, reduzir e transferir o risco. No âmbito do território brasileiro, a Lei ${ }^{\circ} 12.608$ de 10 de abril de 2012, preceitua, em seu parágrafo único do artigo 3, as nuances sobre a integralidade das políticas públicas para atingir as medidas preventivas necessárias à segurança global da população.

Art. $3^{\circ}$ A PNPDEC abrange as ações de prevenção, mitigação, preparação, resposta e recuperação voltadas à proteção e defesa civil. Parágrafo único. A PNPDEC deve integrar-se às políticas de ordenamento territorial, desenvolvimento urbano, saúde, meio ambiente,mudanças climáticas, gestão de recursos hídricos, geologia, infraestrutura, educação, ciência e tecnologia e às demais políticas setoriais, tendo em vista a promoção do desenvolvimento sustentável (Brasil, 2012, p. 2).

Essa deveria ser uma prática generalizada dentro das várias organizações governamentais e e não-governamentais com a finalidade de reduzir danos e prejuízos, e dessa forma, minimizar o risco nas decisões de investimento e abordagem de riscos operacionais como interrupção de negócios, falhas no produção, danos ambientais, impactos sociais e danos como resultado de incêndios e ameaças naturais. $\mathrm{O}$ gerenciamento de riscos é um problema fundamental para todos os setores envolvidos. Isso desde a capacitação de agentes de Proteção e Defesa Civil nos três níveis de governo, com a finalidade de prover conhecimentos específicos e melhores condições de atendimento em situações de desastres, que compreende a logísitica em três fases: pré-desastres, desastres e pós-desastres. Essa última é crucial e tem deixado muito a desejar no cumprimento logístico, que vai desde as demanda por insumos até a entrega no local sinistrado.

Do exposto, a GIRD está empenhada na prevenção de desastres e expressa o conceito e a intenção de evitar completamente os potenciais impactos adversos através de medidas tomadas com antecedência com a premissa de salvaguardar populações e bens.

Dessa forma, a GIRD está definida pelo conjunto de decisões de conhecimento administrativo, organizacional e operacional desenvolvidas por sociedades e comunidades para implementar políticas e estratégias e fortalecer suas capacidaddes de redução dos impactos de riscos naturais e consequentes desastres ambientais e tecnológicos. Isso envolve todos os tipos de atividades, incluindo medidas estruturais e não estruturais para evitar (prevenção) ou limitar (mitigação e preparação) os efeitos adversos de desastres.

\section{Considerações Finais}

Ao longo da história da humanidade, as catástrofes sempre foram uma realidade adversa e imprevisível. 
Porém, com o advento epistemológico que o ser humano vem desenvolvendo nos últimos séculos, mais precisamente a partir do século XIX, tem sido possível prever eventos climatológicos, hidrológicos e meteorológicos com certa antecedência. Tais previsões nos permitem tomar medidas estratégicas que visam mitigar danos e prejuízos. Porém ainda é muito complexo gerenciar tais informações na medida em que as autoridades gestoras negligenciam tais informações, seja por questões econômicas, sociais, ambientais ou até mesmo políticas.

No mundo contemporâneo, é imprescindível que os gestores invistam em gestão de riscos e vulnerabilidades. A falta ou o retardo da GIRD, em inúmeros casos, tem contribuído para perdas econômicas e até humanas irreparáveis e, primordialmente, para o atraso na implantação do ODM, cujas premissas poderiam atenuar a geração de novos riscos.

Diante dessa afirmação, verifica-se que há uma necessidade premente de desenvolvermos mecanismos e metodologias que permitam à população, efetivamente a pessoas residentes em áreas de risco, compreenderem a dinâmica desses eventos e criarem uma cultura prevencionista para que, dessa forma, possam conviver com esses fenômenos.

Por fim, disseminar o tema em epígrafe no seio acadêmico tem grandes perspectivas de gerar novos estudos e pesquisas mais aprofundadas acerca de um assunto tão instigador e motivador, já que o objetivo da GIRD é buscar garantias de promover a segurança global da população.

Como sugestão, verificou-se que possamos levar o tema aos cursos de graduação e de pós-graduação stricto e lato sensu, para que todos tenham entendimento do assunto e possam disseminar de forma técnico-científica as medidas estratégicas para mitigar os efeitos destrutivos do fenômenos físicos naturais desencadeadores de desastres. Com isso, dessa forma, construir uma sociedade com uma cultura voltada para a prevenção, não somente de desastres naturais mas também de desastres antrópicos e, recentemente, para os biológicos como é o caso do vírus COVID-19 (corona vírus) que assola o mundo contemporâneo.

\section{Referências}

ADAMS, J. Risco. Tradução de Lenita Rimoli Esteves. São Paulo: Editora SENAC, 2009.

AGENCIA BRASIL. IBGE: Enchentes Deixaram 1,4 Milhão de Desabrigados Entre 2008 e 2012. Disponível em https://agenciabrasil.ebc.com.br/geral/noticia/2014-04/ ibge-27-dos-municipios-brasileiros-foram-atingidos-porenchentes-afetando-14, acesso em: 05 de mar., 2020.

BECK, U. Sociedade de Risco: Rumo a Uma Outra Modernidade. Tradução de Sebastião Nascimento. São Paulo: Ed. 34, 384 p., 2010.
BRASIL. Glossário de Proteção e Defesa Civil. Ministério da Integração Nacional, Secretaria Nacional de Proteção e Defesa Civil, Departamento de Prevenção e Preparação. Brasília: Ministério da Integração Nacional, 2017.

BRASIL. Plano de Contingência. Módulo de Formação. Elaboração de Plano de Contingência. Livro Base. Ministério da Integração Nacional - MI. Secretaria Nacional de Proteção e Defesa Civil - SEDEC Departamento de Prevenção e Preparação - DPP. 1a Edição. Brasília - DF, 2017. Disponível em https://www.mdr.gov.br/images/stories/ ArquivosDefesaCivil/ArquivosPDF/publicacoes/IIPlano-de-Contingência-Livro-Base.pdf, acesso em 15 de mar., 2020.

BRASIL. Sistema Integrado de Informações sobre Desastres S2iD. Disponível em https://www.mdr.gov.br/protecao-edefesa-civil/sistema-integrado-de-informacoes-sobre-desas tres-s2id, acesso em 15 de mar., 2020.

CASTRO, A.L.C. 2003. CASTRO, A.L.C. 2003. Manual de desastres. Brasília: Ministério da Integração Nacional; Secretaria Nacional de Defesa Civil. v.1. 174p.

CRED. Natural Disasters - 2018. Centre for Research on the Epidemiology of Disasters (CRED). Univerty Catholique of Louvain, Belgiun, 2018.

CRED. Annual Disaster. Statistical Review 2013. Centre for Research on the Epidemiology of Disasters (CRED). Univerty Catholique of Louvain, Belgiun, 2013.

CULTURAMIX.COM. O Histórico de Enchentes no Brasil: Causas e Tragédias. Disponível em https://meioambiente. culturamix.com/desastres-naturais/o-historico-deenchentes-no-brasil-causas-e-tragedias, acesso em 03 de mar., 2020.

FNEM. Região Metropolitana de Fortaleza (CE). Disponível em http://fnembrasil.org/regiao-metropolitana-de-forta leza-ce/, acesso em 17 mai 2020.

IPECE. Ceará em Mapas.Disponível em http://www2.ipece.ce. gov.br/atlas/capitulo1/12/133.htm, acesso em 05 de mar., 2020

LAVELL, A. Reducción Del Riesgo de Desastres en el Ámbito Local: Lecciones Desde la Subregión Andina. Serie: Experiencias Significativas de Desarrollo Local Frente a Los Riesgos de Desastres. Predecan. Comunidad Andina. Primera Edición Lima, Perú, septiembre de 2009.

LAVELL, A. Sobre la Gestión del Riesgo: Apuntes Hacía una Definición. Disponível em: http://cidbimena.desastres.hn/ docum/crid/Mayo2004/pdf/spa/doc15036/doc15036-conte nido.pdf, acesso em 03, mar 2020.

MUSSE, C.; SCHNEIDER, C.; TAVARES, M. O Retrato da Epidemia de Meningite em 1971 E 1974 Nos Jornais O Globo e Folha de S. Paulo. RECIIS - Rev. Eletron de Comun Inf Inov Saúde, v. 9, n. 4 p. 1-13, (2015).

NUNES, L. H. Urbanização e Desastres Naturais. Abrangência América do Sul. São Paulo: Oficina de Textos, v. 14 (1), p. 169-171. 2017.

ONU. Objetivos de Desenvolvimento do Milênio. Disponível em https://nacoesunidas.org/tema/odm/, acesso em: 05 de mar., 2020.

VEYRET, Y. Os Riscos: O Homem Como Agressor e Vítima do Meio Ambiente. Tradutor: Dilson Ferreira da Cruz. São Paulo: Contexto, 2007. 


\section{Endereços de Internet}

História do mundo: https://www.historiadomundo.com.br/curiosi dades/primeiros-seres-humanos.htm.
License information: This is an open-access article distributed under the terms of the Creative Commons Attribution License (type CC-BY), which permits unrestricted use, distribution and reproduction in any medium, provided the original article is properly cited. 